\title{
A degeneração interna da democracia
}

The internal degeneration of democracy

TODOROV, Tzvetan. Os inimigos íntimos da democracia. Tradução de Joana Angélica d'Avila Melo. São Paulo: Companhia das Letras, 2012, 216 p.

\section{Isabela Soraia Backx Sanabria}

isabela_backx@yahoo.com.br

Doutoranda

Universidade Estadual de Campinas

Rua Bela Vista, 23/01 - Vila Areal

13333-020 - Indaiatuba - SP

Brasil

Palavras-chave

Ética; Explicação histórica; Humanismo.

Keywords

Ethics; Historical explanation; Humanism. 
[...] num primeiro momento eu tinha acreditado que a liberdade era um dos valores fundamentais da democracia; agora percebo que certo uso da liberdade pode representar um perigo para a democracia (TODOROV 2012, p. 12).

Para o linguista Tzvetan Todorov, autor da citação acima, o regime democrático é marcado atualmente por um paradoxo: a liberdade irrestrita dos indivíduos ameaça a continuidade da democracia, caracterizada pela defesa dessa mesma liberdade. Nesse sentido, o ultraliberalismo constitui um dos atuais inimigos ao regime, pois muitas vezes alega defender valores nem sempre democráticos. Isso poderia significar que, ao contrário do ocorrido em grande parte do século $\mathrm{XX}$, quando o totalitarismo era seu principal inimigo, as ameaças que hoje pesam sobre a democracia não vêm de fora, mas são cultivadas em seu interior.

$\mathrm{Na}$ obra Os inimigos íntimos da democracia, Todorov desenvolve esse argumento adotando uma perspectiva histórica, procurando demonstrar como os diversos elementos de uma democracia podem chocar-se entre si. Para o autor, quando um desses elementos é absolutizado e rompe o equilíbrio com os outros, emancipa-se de suas responsabilidades e se transforma em uma ameaça da qual podem resultar o populismo, o ultraliberalismo e o messianismo político. Esses seriam alguns dos inimigos íntimos da democracia, perigos que são produzidos por elementos que constituem o próprio regime. Nesse sentido, seria possível afirmar que "[...] o primeiro adversário da democracia é a simplificação que reduz o plural ao único, abrindo assim o caminho para o descomedimento" (TODOROV 2012, p. 19).

A obra em questão é o último livro publicado no Brasil por Todorov. O autor búlgaro, formado em Linguística e radicado na França desde 1963, possui uma extensa produção intelectual que passa pelos estudos em linguística e teoria literária na década de 1970, com obras como Poética da prosa (1971) e Os gêneros do discurso (1978). A partir dos anos 80, volta-se para análises sobre as trocas culturais e o conceito de alteridade, produzindo trabalhos como A conquista da América: a questão do outro (1982). Seu primeiro estudo profundo sobre o totalitarismo vem com a publicação de Em face do extremo (1995), no qual utiliza sua própria experiência para refletir sobre o funcionamento dos regimes totalitários e seus agentes. O tema é retomado no livro aqui analisado, quando Todorov aproxima o totalitarismo e o ultraliberalismo, ambos marcados pelo descomedimento e a falta de equilíbrio entre o poder do Estado e a liberdade dos cidadãos.

A obra Os inimigos íntimos da democracia é dividida em sete capítulos, nos quais o autor aborda um largo período de tempo - compreendido entre o século V e o XXI -, pontuando momentos entendidos por ele como fundamentais para a compreensão de como os elementos povo, liberdade e progresso podem desdobrar-se em ameaças internas à democracia. Para isso, dialoga com autores franceses como o jurista Alain Supiot, o filósofo Jean-Pierre Le Goff e principalmente o também filósofo François Flahault, do qual utiliza diversos conceitos e reflexões (TODOROV 2012, p. 20). 
Curiosamente, o livro não possui prefácio ou introdução, sendo iniciado já com a apresentação do primeiro capítulo, intitulado "O mal-estar na democracia". Nele, o autor revela que a preocupação em estudar as diversas facetas da liberdade provém de sua experiência pessoal: o autor passou os primeiros vinte e quatro anos de sua vida em um regime totalitário, a Bulgária comunista. Ele afirma que, naquela época, a liberdade de expressão era o que mais lhe fazia falta (TODOROV 2012, p. 10).

No entanto, passados quarenta e oito anos, o vocábulo "liberdade" apresenta um problema totalmente distinto para o autor. Ele se ressente não mais de sua ausência, mas de sua utilização indiscriminada, até mesmo para iniciativas que nem sempre acolhem seu assentimento, como em partidos políticos considerados por ele populistas e xenófobos, exemplificados pelo Partido do Povo Dinamarquês, dirigido por Pia Kjaersgaard, e o suíço União Democrática do Centro, comandado por Cristoph Blocher. Sendo assim, questiona-se Todorov:

[...] Haveria aí um indício de que, hoje, as ameaças que pesam sobre ela [a democracia] não vêm do exterior, da parte daqueles que se apresentam como seus inimigos, mas sobretudo de dentro, de ideologias, movimentos ou gestos que alegam defender os valores democráticos? Ou de que os valores em questão nem sempre são bons? (TODOROV 2012, p. 12).

Para Todorov, o principal inimigo enfrentado atualmente pela democracia seria o descomedimento produzido dentro dela mesma. Ele gera forças difíceis de serem neutralizadas, pois o fato de serem produzidas dentro do regime permite-Ihes travestir-se de legítimas pela invocação do espírito democrático. Tal espírito seria composto de um complexo arranjo no qual o progresso, o povo e a liberdade dialogam entre si.

Apesar de ser um conceito suspeito hoje em dia, o progresso seria inerente ao projeto democrático na medida em que este último implica uma crença no aperfeiçoamento da sociedade por meio da vontade coletiva. O povo, por sua vez, é compreendido por Todorov como o grupo de indivíduos que nasceram sob o mesmo solo e daqueles que foram englobados pelos primeiros. Para eles é que as democracias modernas ditas liberais regulam a vida em sociedade de modo a limitar a vontade do indivíduo frente à comunidade e a interferência desta na vida privada dos seus cidadãos. A complexa relação entre esses conceitos produziria aquilo que o autor compreende como regime democrático, em cujo seio estaria a ideia de que "[...] todos os cidadãos são iguais em direitos, todos os habitantes são iguais em dignidade" (TODOROV 2012, p. 16).

Dessa maneira, apesar de não apresentar uma introdução ao livro, Todorov utiliza o primeiro capítulo para introduzir o problema que será desenvolvido em toda a obra, explanar conceitos, justificar a escolha do tema e fazer alguns agradecimentos. Nesse sentido, o artifício de apresentar esta parte como o primeiro capítulo do livro e não separá-la do todo, chamando-a de introdução, poderia ser entendido como uma estratégia adotada pelo autor. Ao recusar a separação entre sua própria história - suas experiências, os motivos que o levaram a escrever, os autores utilizados - e o conteúdo do livro propriamente 
dito, Todorov deixa a entender que não tem interesse em tentar separar sua subjetividade da obra intelectual que vem criando.

No capítulo seguinte, o autor dirige-se ao século $V$ para fazer uma análise histórica da influência que a controvérsia teológica entre Pelágio e Agostinho exerceu sobre os chamados messianismos políticos. Para o primeiro, o principal fundamento do cristianismo seria o de possibilitar ao homem a tomada do próprio destino nas mãos. Ao defender que a vontade dos homens, assim como a de Deus, era infinita, acreditava que eles possuíam a capacidade de ultrapassar qualquer tipo de limite, podendo até mesmo se tornar deuses e senhores de seus destinos. Nesse sentido, a principal exigência do cristianismo não deveria ser a de submissão à Igreja, mas a de autocontrole e força de vontade, que levariam à autonomia do indivíduo. O homem seria responsável por sua própria salvação.

Agostinho opunha-se ferrenhamente a essas ideias. Para ele, o homem não era dono de suas vontades e nem das forças que o dirigiam, de modo que não poderia confiar em sua própria força e exigir dela sua salvação. Esta se daria somente através da obediência aos preceitos da Igreja.

Na época, o debate é vencido por Agostinho e as ideias de Pelágio são declaradas heréticas. No entanto, essas últimas foram resgatas, principalmente a partir da Renascença, por pensadores como Erasmo de Roterdã e Montaigne, os quais se empenharam em defender as capacidades humanas - razão pela qual ficaram conhecidos como humanistas -, e também por iluministas como Montesquieu e Rousseau. Estes, baseados na ideia de autonomia, sustentavam a responsabilidade do indivíduo não só pela sua salvação, mas também pelo aperfeiçoamento da sociedade. Tal reflexão levou a uma inversão de valores que radicalizou o pensamento pelagiano a partir do século XVIII, quando as apreensões com os indivíduos passaram a ser substituídas pela preocupação com a coletividade, levando posteriormente a que os debates eruditos fossem substituídos por ações políticas.

Apoiados nessa lógica, os revolucionários franceses passaram a entender que a luta pela progressão infinita da humanidade deveria ser ilimitada, mesmo que se desse pelas armas. "Como se trata do Bem supremo, todos os caminhos seguidos para atingi-lo são bons $[\ldots]$, e tem-se o direito de destruir os que se opõem a essa intenção" (TODOROV 2012, p. 42).

No terceiro capítulo da obra, intitulado "O messianismo político", Todorov analisa essa radicalização do pensamento de Pelágio, demonstrando como fundamentaria a ideia de que a vontade humana, desde que comum, poderia trazer a salvação a toda a humanidade. É em tal pensamento que o messianismo político estrutura suas bases; ele postula que é por meio dos movimentos sociais que os homens conseguirão instaurar um paraíso na Terra. Trata-se de um projeto que busca a salvação temporal por meio da Revolução e do terror, afastando-se da religião mas mantendo alguns traços dela, como a fé cega nos dogmas revolucionários, o fervor nas ações e a adoração dos combatentes caídos como mártires e até mesmo santos.

Tal raciocínio vai fundamentar, num primeiro momento, as guerras revolucionárias e coloniais. O projeto de levar um "Bem" maior a todos os 
povos da Terra será utilizado primeiramente pela França e a Inglaterra para construírem seus impérios e, posteriormente, embasará também os discursos sobre a superioridade racial dos europeus.

A fase seguinte desse projeto messiânico será caracterizada pela crença de que uma grande e última revolução transformaria para sempre a sociedade. Para Todorov, esse é o momento em que surge o projeto comunista, definido como um messianismo político devido a seu desejo pelo aperfeiçoamento de todos os aspectos da vida de um povo, desde as instituições aos seres humanos, não hesitando em recorrer às armas para isso.

Por último, a derradeira fase do messianismo político seria a de imposição de regimes democráticos e de direitos humanos a outros países, como ocorreu na Guerra do Afeganistão, do Iraque e da Líbia. Os três conflitos foram permeados pela ideia de que, se em tais regiões ocorriam violações aos direitos humanos, os outros países do globo tinham o direito e o dever de intervir, mesmo que à força. No entanto, Todorov sustenta que tais guerras, justificadas pelo governo dos Estados Unidos como uma defesa pela autodeterminação dos povos e dos direitos humanos, haveriam sido, na verdade, uma maneira de reafirmar o poderio militar americano e conquistar benefícios econômicos. Dessa maneira, procura demonstrar como o messianismo político age em nome de um Bem maior, mas acaba voltando-se para interesses particulares.

No quarto capítulo da obra desenvolve-se a análise de outro inimigo gerado internamente pela democracia: a tirania dos indivíduos. Segundo o autor, há hoje em dia uma inversão dos valores totalitários. Enquanto esses valores se baseavam na hipertrofia do individual em nome do coletivo, atualmente ocorre uma valorização do indivíduo que, muitas vezes, leva ao apagamento da coletividade. Tal inversão seria uma resposta dos pensadores neoliberais aos regimes totalitários, mas, ao recusar qualquer interferência do Estado na economia, os neoliberais acabam assumindo traços do regime que tanto condenam.

Todorov levanta contundentes críticas a esse modelo ultraliberal. Para ele, se o Estado não limita a ação dos indivíduos, estes adquirem um poder sempre crescente que será exercido sobre outras pessoas. Nesse caso, dar liberdade a todos não é garantir sua igualdade, visto que o indivíduo com mais poder - seja ele financeiro, de expressão ou de qualquer outro tipo - irá estabelecer uma relação de superioridade com os outros e sobre eles.

Os efeitos trazidos pelo neoliberalismo são o objeto de análise do quinto capítulo. Entre eles estaria o uso imoderado das novas tecnologias visando somente ao lucro - sem preocupar-se com as consequências sobre os seres humanos - e o papel significativo da liberdade de expressão. Esta última não poderia funcionar como o fundamento comum dos valores democráticos, mas deveria sofrer restrições relativas aos outros valores que são aderidos a ela numa sociedade. Tal proposição pode parecer, num primeiro momento, um ataque direto do autor à liberdade de expressão. Apesar disso, Todorov apresenta uma justificativa fundamentada para esse posicionamento: a total liberdade de expressão fornece aos indivíduos o direito de exprimir qualquer pensamento, até mesmo os de cunho racista, discriminatório ou pejorativo. 
Sendo assim, o autor defende a imposição de limites à liberdade dos indivíduos, da mesma maneira que foram impostos limites à liberdade do Estado. Este, por sua vez, deveria ser gerido de maneira equilibrada e eficaz, de modo a poder conter não somente as ações de grupos terroristas, mas também as de indivíduos hiperpoderosos que controlam as mídias e certos setores da economia.

Os últimos inimigos da democracia identificados pelo autor são o populismo e a xenofobia, tratados no penúltimo capítulo. O populismo teria como base a prática da demagogia, entendida por Todorov como o processo de identificação das preocupações do maior número de pessoas e a proposição de soluções fáceis, mas impossíveis, para saná-las. Um dos efeitos mais nefastos desse tipo de discurso seria a marginalização daquela parte da sociedade que possui culturas e necessidades diferentes das da maioria.

Quanto à xenofobia, esta teria lugar marcado atualmente na sociedade europeia. Apoiados em discursos populistas, diversos partidos têm rejeitado o multiculturalismo - a coexistência de várias culturas dentro de uma mesma sociedade - em prol da preservação de uma suposta cultura nacional, voltando-se principalmente contra os estrangeiros e identificando-os como a origem de diversos problemas.

Tanto o populismo como a xenofobia estariam profundamente ligados à crise de identidade que perpassa atualmente a sociedade europeia. Para Todorov, o sentimento de um abalo da identidade tradicional estaria ligado às mudanças trazidas pela globalização e o crescimento do individualismo. No entanto, tais elementos são impalpáveis, ao passo que a grande quantidade de estrangeiros imigrantes, sintoma dessa globalização, não o é. Aproveitando-se disso, passaram a surgir na Europa diversos discursos populistas que projetaram nos imigrantes - sobretudo nos muçulmanos - o grande inimigo.

A obra é encerrada no capítulo sete, com um debate sobre o possível futuro da democracia. Tal regime estaria sendo corroído internamente por seus inimigos íntimos, não estando mais à altura de suas promessas. Essa constatação é, para o autor, uma grande preocupação, já que revela que o inimigo se encontra dentro de nós mesmos. Em suas próprias palavras,

[...] A democracia está doente de seu descomedimento: a liberdade torna-se tirania, o povo se transforma em massa manipulável, o desejo de promover o progresso se converte em espírito de cruzada. A economia, o Estado e o direito deixam de ser meios destinados ao florescimento de todos e participam agora de um processo de desumanização (TODOROV 2012, p. 197).

A solução proposta pelo autor é a tomada da ação, a construção de resistências contra esses inimigos que podem acabar por esvaziar a democracia de sua substância. Nesse sentido, a ação refere-se à imposição de restrições à ultraliberdade: "[...] a liberdade absoluta dos indivíduos não é um objetivo desejável; é próprio das sociedades humanas constituírem-se a partir de proibições e de regras que organizam a vida comum" (TODOROV 2012, p. 195).

Para finalizar, é importante frisar que o livro Os inimigos íntimos da democracia é característico da produção intelectualmente engajada produzida 
por Tzvetan Todorov. No subtítulo "Viver melhor juntos", o autor aponta uma série de elementos e atitudes a serem adotadas para que autóctones e estrangeiros possam conviver melhor. Entre elas estaria o respeito aos costumes e às leis, além da criação de uma memória em comum.

Dessa maneira, a obra parece não se restringir a uma análise teórica, mas apresenta também certo tipo de metodologia, um conjunto de práticas que poderiam auxiliar na instauração de uma democracia justa e que de fato abarcasse a todos. Apesar de tal objetivo ser negado pelo autor, ele mostra ser um intelectual engajado, um estudioso que procura por meio de seu trabalho modificar o mundo a sua volta, sem a pretensão de esconder sua própria história ou subjetividade.

O livro apresenta uma importante análise sobre os regimes democráticos modernos, auxiliando-nos a identificar e compreender certos problemas que por vezes parecem-nos naturais a uma democracia. Ao traçar os paradoxos existentes dentro desse regime, o autor nos ajuda a compreender que uma democracia liberal não é o lugar em que "tudo vale", mas sim em que todos têm lugar.

A obra torna-se uma referência para a compreensão de certas engrenagens que fazem funcionar os Estados-nação, mas também nos auxilia de maneira admirável a entender o momento político vivido atualmente no Brasil, marcado por manifestações e reivindicações diversas que têm em comum a insatisfação da população com um Estado democrático que não atende às suas expectativas e necessidades básicas.

\section{Referências bibliográficas}

TODOROV, Tzvetan. Poética da prosa. São Paulo: Martins Fontes, 1979. Os gêneros do discurso. São Paulo: Martins Fontes, 1980.

A conquista da América: a questão do outro. São Paulo: Martins Fontes, 1982.

. Os inimigos íntimos da democracia. Tradução de Joana Angélica d'Avila Melo. São Paulo: Companhia das Letras, 2012. 